\title{
Pedagogia e Didática: Relações e Aplicações no Ensino Médico
}

\author{
Pedagogy and Didactics: Relations and \\ Applications in Medical Education
}

Ernesto Lima Gonçalves ${ }^{1}$

DESCRITORES

- Educação médica

KEYWORDS

- Medical education

\section{ABSTRACT}

The author examines the three watersheds (philosophical, scientific, and technical) in pedagogy in order to introduce their application to the medical education process. He then analyzes the materialist and humanist schools of pedagogical thinking, as well as the behaviorist, Gestalt, and constructivist theories of learning. The technical watershed, represented by didactics, is examined through the transition from the traditional position to

contemporary experience.
\end{abstract}

São examinadas as três vertentes da pedagogia a filosófica, a científica e a técnica para introduzir sua aplicaçăo no processo de educaçõo médica. Săo analisadas as correntes materialista e humanista do pensamento pedagógico, bem como as teorias comportamentalista, gestáltica e construtivista da aprendizagem. A vertente técnica, representada pela didática, é examinada na passagem da posição tradicional até os momentos contemporâneos. 


\section{INTRODUÇÃO}

Ao falar em educaçåo médica, é útil retomar o conceito fundamental de que a educação pode ser assumida como o conjunto de competências intelectuais e manuais que se deve adquirir e de qualidades morais que é preciso desenvolver ao longo de uma vida. Trata-se de processo eminentemente humano, o que obriga a uma reflexão conceitual mais ampla do que habitualmente se faz. A educação consiste, em última análise, no processo que oferece ao educando orientaçōes e elementos para que possa realizar-se plenamente como ser humano.

É importante salientar que, ao se fazer referência a "educando", não há por que fixar-se apenas na figura da criança; importa trazer à tona o perfil de qualquer pessoa, de qualquer idade, que participe como objeto do processo educacional. Mais adiante, a informação será completada com o reconhecimento de que o educando, mais do que objeto, é sujeito do processo. Nessa linha de elaboraçăo, coloca-se o estudante de medicina, que se encontra em pleno processo de adquirir qualidades intelectuais conhecimentos, bem como qualidades manuais habilidades, ao lado de desenvolver qualidades morais comportamentos ou atitudes, todos igualmente essenciais a um futuro exercicio profissional bem-sucedido.

Nessa atividade, cabe ao futuro médico reconhecer que a medicina é, acima de tudo, encontro entre pessoas, o que exige nova reflexão conceitual. O homem é um ser que existe na atureza com as mesmas características que os demais seres, vivos ou inanimados. Tal como os animais ou vegetais, de um lado, e os minerais, de outro, o homem está sujeito a determinismos físicos opacidade e ocupação de lugar no espaço, por exemplo ou biológicos, como a necessidade de garantir a sobrevivência própria, pela satisfação da fome e da sede, ou da espécie, pelo exercício da sexualidade. Todas essas características fazem do homem um indivíduo, como são todos os outros seres da natureza.

Mas o homem tem dentro de si algumas marcas que o privilegiam no contexto dos emais indivíduos. Apenas ele na natureza é dotado de racionalidade, condição que o torna capaz de abstração e de integração de novas experiências aos conhecimentos anteriores. Também apenas o homem é dotado de liberdade, capacidade de escolher, a cada momento, entre diferentes alternativas de toda natureza que se colocam à sua frente. Por último, apenas o homem é capaz de, após ter feito sua escoTha entre diferentes caminhos possíveis, assumir a responsabilidade pelas consequências da opção realizada. Tais características fazem com que o homem seja uma pessoa, além de ser um indivíduo.

Tais consideraçoes é que permitem melhor compreensão do "encontro entre pessoas ${ }^{*}$ de que se falou. Permitem entender que, ao lado de procurar conhecer a biologia de seu doente, deve o médico e isso é ainda mais importante conhecer sua biografia.

O estudo do processo educacional denomina-se Pedagogia, expressão que pode ser assumida como "filosofia, ciência e técnica da educação ${ }^{\circ} .6$ Très vertentes desse mesmo tema merecem ser apreciadas separadamente.

\section{A VERTENTE FILOSÓFICA DA PEDAGOGIA}

A análise, sem pretender maior aprofundamento, permite identificar duas correntes básicas de pensamento pedagógico: o materialismo e o humanismo.

O materialismo distingue no homem apenas sua dimensåo material e biológica. Para Rousseau, essa proposta já se colocava na linha do naturalismo: "o homem nasce bom e a sociedade o corrompe". A partir dessa afirmaçăo, pode-se imaginar que a criança deve crescer de acordo com a natureza, livre de toda restrição da sociedade e, se possível, longe dela. Tal proposta foi levada à risca com a experiência educacio. nal de Summerhill. É bem verdade que, há alguns anos, ex-alunos dessa instituição voltaram a ela... para incendiá-la. Hereditariedade e ambiente fisico são os únicos fatores admitidos na formaçăo do homem. Podese, então, entender a afirmação de Dewey: "o processo educacional não tem outro fim além dele mesmo; ele é seu próprio fim e consiste em contínua reorganização, reconstrução e transformação ${ }^{\circ}{ }^{4}$

Esta referência merece um comentário. Em primeiro lugar, porque Dewey foi dos nomes de maior relevo do movimento pedagógico denominado "escola nova", que chegou ao Brasil principalmente pelo espírito inovador de Anísio Teixeira. A essa corrente de pensamento educacional filiava-se Flexner, nome que se incorporou à educação médica, como adiante se verá. De outra parte, a "organização, reconstruçāo e transformaçăo" de que Dewey falava foram retomadas mais tarde pelos educadores que estruturaram a teoria construtivista da aprendizagem.

O humanismo, ao estudar o processo educacional, procura identificar toda a complexa estrutura da natureza humana. Para a corrente materialista, o homem é mero animal, embora já seja reconhecido como animal social. Para os humanistas, o homem é um ser dotado de racionalidade e capaz de emoçôes; hereditariedade e ambiente físico săo, por certo, fatores de formaçăo do homem, mas há um terceiro fator, superior aos outros dois, que é o próprio homem enquanto pessoa, dotado de racionalidade, liberdade e responsabilidade. O processo educacional, objeto do estudo da pedagogia, năo pode, pois, deixar de considerar tais marcas essenciais do homem, se pretender abrir-lhe os caminhos de completa estruturação de personalidade. Por esse caminho é que se pode repetir que "a educação não gera médicos, cirurgiøes, engenheiros, soldados, banqueiros ou comerciantes, mas homens ${ }^{\circ}$. $^{2}$

\section{A VERTENTE CIENTÍFICA DA PEDAGOGIA}

Ainda que se reconheça que a ciência năo consegue abranger $\mathrm{e}$ explicar toda a complexidade de que se reveste a natureza, é de reconhe- 
cer que existem contribuiçoes indiscutiveis para o conhecimento do processo educacional, oferecidas particularmente pelas "ciências do homem", em especial a biologia, sociologia e psicologia. Isoladamente ou conjugadas, elas oferecem suporte para a investigaçăo e o conhecimento das teorias da aprendizagem humana.

Apenas como tentativa de esboçar um quadro, que é muito mais complexo do que aquele que será aqui desenhado, é possivel identificar o que se pode denominar teorias da aprendizagem: a comportamentalista, a gestáltica e construtivista.

A teoria comportamentalista é estreitamente vinculada aos conceitos de condicionamento, desdobrados desde os estudos tradicionais de Pavlov e das aplicaçðes de Thorndike, que procurou estabelecer uma "relaçăo entre uma situação reclusão numa caixa de certa aparência e a resposta $R$ arranhadura de determinada parte da caixa executada de determinada maneira*.

A repetição é indiscutivelmente fator de aprendizagem, e os conceitos decorrentes do "reflexo condicionado" e dos condicionamentos de fundo biológico foram incorporados pela escola psicológica dos comportamentalistas (behavioristas); o comportamento dos indivíduos seria determinado pelos condicionamentos colocado o estímulo $\mathrm{S}$, a resposta $\mathrm{R}$ é inevitável. Daí a afirmação de Cunningham de que "a conduta pode ser submetida a controle muito mais do que pensa o homem comum. Na expressão de James todos nós somos "faixas ambulantes de hábitos ${ }^{*}{ }^{3}$ Ignora-se aqui a característica fundamental da pessoa humana, representada pela liberdade.

$\mathrm{Na}$ linha dos behavioristas, toda motivaçăo nasce ou diretamente dos impulsos orgânicos ou de emoçoes básicas, formados dentro do organismo e de cuja determinação ele não pode escapar. Aos olhos dos behavioristas, a aprendizagem é uma mudança mais ou menos permanente do comportamento, que ocorre como resultado da prática repetitiva; o processo educacional consistiria em imprimir novas reaçðes sobre organismos maleáveis, passivos.

À medida que outras teorias relativas aos mecanismos psicológi$\cos$ da aprendizagem foram surgindo, a corrente comportamentalista nos anos mais recentes foi sendo identificada como "neobehaviorista", não implicando essa denominação qualquer proposta de alteração substancial de posição. Mas introduziu-se a categorização do condicionamento em condicionamento clássico sem reforço e condicionamento instrumental que ocorre por meio de reforço. O encorajamento educacional deve tomar a forma de reforços positivos ou negativos: positivo será o estímulo cuja presença reforça um comportamento; negativo será o estímulo cuja retirada fortalece um comportamento.

A aplicação da teoria do reforço ao processo de aprendizagem encontra, naturalmente, ampla e variada aplicação. Basta lembrar, por năo ser de utilização frequente, a significaçăo que pode assumir no desempenho do aluno a identificação por ele dos resultados obtidos em etapas sucessivas do processo. Daí o interesse em introduzir, ao longo de um programa, momentos de interrupça, marcados por uma avaliação do segmento estudado. Os resultados dessa avaliação poderão funcionar como reforço para a evolução da aprendizagem.

Skinner, grande nome do terreno da teoria do reforço, manifesta-se convencido de que os pesquisadores iniciais exploraram demais o princípio do condicionamento reflexo, atribuindo-lhe um crédito exagerado. Adverte, contudo, que ignorar completamente o princípio do comportamento reflexo seria injustificável. Mas "não é plausivel nem conveniente conceber o organismo como complicada caixa de surpresas com grande repertório de truques, cada um dos quais podendo ser evocado pela pressão do botão adequado ${ }^{15}$

É preciso lembrar que o reforçamento difere basicamente da punição: enquanto o reforço envolve apresentaçăo de um elemento reforçador positivo ou remoçăo de um negativo, a punição consiste na apresentação de um estímulo negativo ou na retirada de um positivo; enquanto o reforçamento é definido em termos de fortalecimento de uma resposta, a punição é provavelmente um processo que enfraquece a resposta.

A teoria gestáltica rejeita a proposta de Thorndike, de relação na proporção 1:1, preferindo abordar a questão do ponto de vista da percepção global da situação, traduzida na expressão alemã gestalt. Mas, uma vez que se procura identificar determinada situação como um todo para alcançar melhor conhecimento do problema, pode-se utilizar a expressão "configuração"; dai falar-se também de teoria configuracionista, que busca o conhecimento de um "todo organizado em contraste com uma coleção de partes ${ }^{*}$.

Em cada situaçăo percebida, aparecem aspectos que representam mais do que aqueles apreendidos pelos sentidos. Um observador tende a conferir aos elementos físicos da percepção um formato, uma configuraçăo ou um significado, tenta organizar ou integrar tudo quanto vê. Todo professor sabe muito bem como reagem os alunos à situação global da classe; eles săo influenciados não apenas pelo desafio da questão formulada ou do conhecimento novo a ser fixado, mas também pelo tom de voz do professor, por sua expressão facial, pela atitude dos outros alunos e até pela temperatura da sala. Como o aprendizado é condicionado pelo comportamento do grupo, é fácil perceber que critérios extraídos da sociologia enriquecem o conteúdo e a análise.

No quadro de referência da escola gestáltica, a motivaçăı não pode ser descrita meramente como um impulso para a ação disparado por um estímulo. Ela, na verdade, emerge de uma situaçăo psicológica dinâmica, caracterizada pelo desejo de fazer algo. Um psicólogo gestaltista vê a motivaçăo como um produto de desequilibrio, que inclui objetos a serem atingidos e barreiras a serem superadas. Um objetivo pode ser 
positivo ou negativo algo que se quer obter ou algo que se deseja evitar. Quando aparece uma barreira à obtenção direta e imediata, a pessoa entra em tensão. Tenta, então, reduzi-la, superando ou contornando a barreira; a motivaçăo corresponde ao impulso para se libertar da tensão, continuando em direção ao objetivo. ${ }^{11}$

Os psicólogos gestaltianos vêm o aprendizado como um empreendimento agradável, imaginativo, criativo. Este conceito rompe completamente com a idéia de que a aprendizagem consiste apenas na ligação entre uma coisa a outra, conforme certos princípios de associaçăo, ou na construção de comportamentos de um modo determinista e mecanicista. O processo de aprendizagem identifica-se melhor com pensar e organizar idéias, um processo que está longe de ser mecânico, porque está repleto de criatividade.

A teoria construtivista recebe sua denominaçăo a partir do princípio fundamental em que se baseia, segundo o qual o conhecimento, mais do que aprendido pelo aluno, dever ser "construído" por ele. Os educadores que se filiam a esta escola consideram fundamental o fato de que a pessoa está interagindo continuamente com o meio ambiente, de que resulta uma mudança contínua denominada adaptação, que supoe um processo de assimilação e de acomodação.

Assimilação é a aplicação dos esquemas ou experiências anteriores do individuo a uma nova situação, incorporando outros elementos a seus modelos anteriores. Acomodaçăo é assumida como a reorganização e modificação dos esquemas assimilatórios anteriores para ajustálos a cada nova experiência.

Quando uma pessoa se depara com uma situação desafiadora, mesmo no campo de aquisição de conhecimentos ou de desenvolvimento de atitudes e comportamentos, sem que seus esquemas mentais disponham de elementos suficientes para enfrentar o desafio, ocorre um desequilíbrio momentâneo. Então, a pessoa ativa seus esquemas assimilatórios, retirando do meio as informaçoes necessárias, e mobiliza seus esquemas de acomodação, reorganizando os novos dados e superando a situação de desafio; gera-se, dessa maneira, um novo estado de equillbrio. Trata-se de verdadeira construção da personalidade, marcada pelo alto dinamismo que caracteriza todos os fatos humanos, ${ }^{5}$

Na palavra de Piaget, um dos grandes elaboradores desta teoria da aprendizagem, "a cada instante a ação é desequilibrada pelas transformaçoes que aparecem no mundo exterior ou interior e cada nova conduta vai funcionar não apenas para restabelecer o equilibrio, como também para tender a um equilibrio mais estável do que o estágio anterior. A ação humana consiste neste movimento contínuo e perpétuo de reajustamento ou reequilibração ${ }^{*}{ }^{14}$

A aprendizagem caracteriza-se, então, como um processo altamente dinâmico, que depende da atividade mental do educando e que se desenvolve pela mobilização de seus esquemas de raciocínio. Para isso, o ensino deve apelar para a atividade mental do aluno, levando-o a observar, manipular, perguntar, pesquisar, trabalhar, construir, pensar e resolver situaçðes problemáticas.

O construtivismo inaugura a valorizaçăo do agir de quem aprende como elemento central para o aprendizado. Este resulta da interaçăo entre as estruturas do pensamento de alguém e o tema que precisa ser ensinado; daí a necessidade de possibilitar que a inteligência e a atividade do aluno ajam sobre o que deve ser aprendido. A elaboração é novamente de Piaget: "compreender é inventar ou reconstruir através da reinvençăo, e será preciso curvar-se ante tais necessidades se o que se pretende para o futuro é ter indivíduos capazes de produzir ou de criar e não apenas de repetir".

$* * *$

A análise, tăo superficial quanto o espaço permite, revela que cada uma das três teorias da aprendizagem expostas apresenta elementos e aspectos em si mesmos indiscutiveis. Daf porque não se compreende a fixação teimosa de alguns educadores numa ou noutra. Trata-se de postura que empobrece o contexto educacional, porque limita o processo a este ou aquele aspecto que cada teoria prioriza. Mais inteligente e, por isso mesmo, mais educativa será a absorção de tudo quanto cada uma traz de positivo e construtivo, para a compreensăo e o desenvolvimento satisfatório do processo educacional. Assim como educativa será a compreensāo do momento emocional do aluno, somatório de emoçōes antigas e novas, capazes de condicionar o desejado sucesso no processo de aprendizagem. ${ }^{10}$

\section{A VERTENTE TÉCNICA DA PEDAGOGIA: A DIDÁTICA}

É essencial, em primeiro lugar, situar de maneira adequada a expressão técnica, que, longe de assumir qualquer sentido restritivo ou pejorativo, abrange o espectro mais amplo do processo educacional, uma vez que compreende o sentido de como ensinar, ou seja, de concretizar tudo quanto as correntes filosóficas ou as teorias de aprendizagem propōem. Aguayo define a didática como "a técnica de estimular, dirigir e encaminhar, no decurso da aprendizagem, a formaçăo do homem".

Com base nas contribuiçōes das ciências do homem, a didática procura identificar as melhores estratégias e os instrumentos mais eficientes para o desenvolvimento do processo educacional, dentro de cada realidade ambiental e circunstancial. Os resultados, contudo, săo obviamente vinculados de maneira estreita ao comportamento do educador.

Tradicionalmente, a relaçăo professor-aluno tem sido autoritária. Mas importa voltar à conceituação de Aguayo, para lembrar que estimular e encaminhar diferem substancialmente de substituir e impor, donde a clara consequência, formulada anteriormente: ao longo do processo 
de ensino-aprendizagem, numa estimulante interação professor-aluno, o conhecimento deve ser construido pelo educando, mais até do que aprendido por ele. A evolução que permitiu chegar a esta concepção está muito bem resumida no Quadro 1, de autoria de Ferreira. ${ }^{6}$

No contexto do que foi exposto até aqui sobre o processo de ensino-aprendizagem, é que se podem introduzir as aplicaçōes no campo da educação médica. Conceitualmente, existem amplas perspectivas para a aplicaçăo das teorias da aprendizagem à educação médica. ${ }^{9}$ Do ponto de vista metodológico, igualmente, propostas muito consistentes têm sido formuladas e implementadas, entre as quais a "aprendizagem baseada em problemas*.
Na passagem do século, o ensino médico era essencialmente livresco, carente de base científica e, ao mesmo tempo, marginalizador do aluno, uma vez que se baseava na aula magistral. Nos Estados Unidos, a situação era denunciada pelo grande Osler, ao afirmar que "laboratórios bem montados, a cargo de homens perfeitamente preparados como mestres e pesquisadores, eis a mais premente necessidade atual das escolas médicas deste país. ${ }^{\cdot 13}$ Na mesma época, entre nós, o mestre Miguel Couto dizia em seu discurso de posse na Academia Brasileira de Letras: "a clínica deve aliar-se profundamente ao laboratório, que pesa, mede, controla e coloca fronteiras da realidade contra nossa imaginaçāo*.

QUADRO 1

\begin{tabular}{|c|c|c|c|}
\hline $\begin{array}{l}\text { Fontes } \\
\text { Elementos } \\
\text { básicos de } \\
\text { Didática }\end{array}$ & $\begin{array}{c}\text { I-Didática } \\
\text { Tradiciona }\end{array}$ & $\begin{array}{l}\text { II-Transição } \\
\text { (Escola Nova) }\end{array}$ & $\begin{array}{l}\text { III-Didática } \\
\text { Contemporânea }\end{array}$ \\
\hline Professor & $\begin{array}{l}\text { - agente principal do processo de } \\
\text { ensinar. } \\
\text { - cumpridor de programa. } \\
\text { - autocrata }\end{array}$ & $\begin{array}{l}\text { - valorizador do processo } \\
\text { ensino-aprendizagem. }\end{array}$ & $\begin{array}{l}\text { - facilitador da ação educativa. } \\
\text { - orientador da aprendizagem }\end{array}$ \\
\hline Aluno & $\begin{array}{l}\text { - receptor passivo } \\
\text { valorizado em função da } \\
\text { inteligência, mente, intelecto e } \\
\text { capacidade de reter } \\
\text { ensinamentos. }\end{array}$ & $\begin{array}{l}\text { centro do processo } \\
\text { ensino-aprendizagem. }\end{array}$ & $\begin{array}{l}\text { - "autor" da própria } \\
\text { aprendizagem. }\end{array}$ \\
\hline - Objetivo & $\begin{array}{l}\text { - desligado da realidade do aluno. } \\
\text { Formulado em termos de } \\
\text { conteúdo ou dos procedimentos } \\
\text { utilizados }\end{array}$ & - tentativa de informar para a vida. & $\begin{array}{l}\text { - estabelecido com base na } \\
\text { realidade do aluno. } \\
\text { - formulado em função do } \\
\text { rendimento mensurável do } \\
\text { aluno, isto é, do que ele pode } \\
\text { fazer ou como se comportará ao } \\
\text { final de determinado período. }\end{array}$ \\
\hline Conteúdo & $\begin{array}{l}\text { rol completo de informaçöes a } \\
\text { serem estudadas pelo aluno. } \\
\text { acúmulo de dados considerados } \\
\text { como verdades absolutas. } \\
\text { fonte de conhecimento. }\end{array}$ & $\begin{array}{l}\text { - conjunto de assuntos da } \\
\text { experiência do aluno. }\end{array}$ & $\begin{array}{l}\text { - conteúdo selecionado e } \\
\text { programado numa perspectiva } \\
\text { dinâmica. } \\
\text { - interessado no desenvolvimento } \\
\text { harmônico do aluno que envolve } \\
\text { a área cognitiva, afetiva e } \\
\text { psicomotora. } \\
\text { - em vista do ajustamento e } \\
\text { auto-realização do aluno no meio } \\
\text { em que vive }\end{array}$ \\
\hline - Método & $\begin{array}{l}\text { - apelo à memorização. } \\
\text { - aprender repetindo. }\end{array}$ & - aprender a fazer fazendo. & $\begin{array}{l}\text { - antecipação e preparo dos } \\
\text { procedimentos ou condições } \\
\text { exteriores úteis à aprendizagem } \\
\text { pessoal e integradora. }\end{array}$ \\
\hline
\end{tabular}


A grande guinada na educação médica ocorreu após um amplo trabalho desenvolvido, nos primeiros anos deste século, por uma comis. são especialmente constituída pela Fundação Carnegie e cuja coordenação coube a um educador americano. Abraham Flexner; o objetivo era analisar a situação do ensino médico nos Estados Unidos e Canadá. O relatório final da comissão passou à história do ensino médico como "relatório Flexner", tendo sido publicado em 1910.

A proposta final da comissão foi não apenas reduzir drasticamente o número de escolas médicas existentes, mas principalmente modificar o padrão educacional vigente. Valeu, entåo, a presença de Flexner e sua sensibilidade de educador: companheiro de Dewey, vivenciava plenamente os princípios da "escola nova", os quais se esforçou por transferir para o processo de educação médica.

Sensível à denúncia de Osler a respeito da carência de formação científica dos docentes médicos, a proposta de Flexner baseava-se no esforço de oferecer-lhes a melhor formação científica possível. Pode-se dizer que, a partir daquele momento, o estetoscópio passava a ter a companhia da pipeta e do microscópio como instrumentos de trabalho do professor de medicina. No limite, cada docente médico devia tender a tornar-se um cientista.

Flexner foi mais adiante: a partir dos critérios da "escola nova", introduziu na educação médica o conceito de que o conhecimento deve ser construido pelo aluno: "sob o aspecto pedagógico, a medicina moderna, como todo o ensino científico, é caracterizada pela atividade: o estudante não mais apenas vê, ouve e memoriza, ele faz. Suas próprias atividades na enfermaria e no laboratório são os principais fatores de sua instrução ${ }^{*}$ ?

Considerando o embasamento científico que se passava a exigir do professor de medicina, o melhor local para desenvolver toda a atividade educacional, colocado a serviço da formação do aluno, deveria ser o hospital. "Aqui [no hospital de ensino] o estudante toma a história do doente, conduz o exame clinico, realiza exames microscópicos e laboratoriais, propõe o diagnóstico, sugere o tratamento. Para tanto, ele tem acesso fácil a todos os setores do hospital, seus leitos estão sob sua contínua observaçăo, desde o dia em que (seu( paciente é admitido até o momento da alta ou o advento do óbito"?

É preciso não esquecer que o modelo flexneriano, resumidamente apresentado, foi formulado e desenvolvido na primeira década deste século. Disto deveriam lembrar-se todos os que, com rapidez e superficialidade, criticam Flexner, impressionados com as distorçōes que o modelo possa ter sofrido. A mais importante delas reporta-se certamente ao papel fundamental que se veio a atribuir ao hospital de ensino no desenvolvimento do processo de educação médica. A crítica é aqui procedente, porque, nos anos mais recentes, por toda parte surgiram modelos de atendimento da populaçăo, compreendendo agências de saúde, de diferentes capacidades e distintos níveis de complexidade.
Dai a proposta do modelo ideal, de utilizar uma rede em que tais agências sejam regionalizadas e hierarquizadas, tendo o hospital no alto da pirâmide assistencial.

Percebe-se que a educação médica pode, com grande proveito, ser desenvolvida em qualquer dos níveis dessa rede e não apenas no hospital. O conceito tomou impulso com o movimento de "Medicina Social/ Preventiva", que dos Estados Unidos se expandiu por toda parte, tal é a lógica de seus argumentos.

As críticas habitualmente formuladas ao modelo flexneriano não podem jamais fazer esquecer a grande contribuiçāo pedagógica que Flexner pôde introduzir no panorama da educação médica. A objeçăo que se faz a respeito do monopólio que o hospital de ensino conquistou no processo vem assumindo, nos últimos anos, mais uma razão de reforço. $\mathrm{O}$ argumento é que o hospital de ensino corre o risco de se transformar numa verdadeira "catedral de tecnologia".

A incorporação dos mais recentes progressos tecnológicos permitiu indiscutível avanç̧o nos terrenos tanto diagnóstico quanto terapêutico. Tudo isso é com razăo apresentado ao estudante, embora, muitas vezes, sem uma crítica adequada e judiciosa a respeito de seu uso. Naturalmente, não ocorre a nenhum docente médico omitir informaçōes a respeito do alcance de todos os modernos recursos tecnológicos disponíveis na área da saúde. Mas é importante lembrar sempre que se trata apenas de recursos complementares, que não podem se transformar em efetores do diagnóstico, substituindo o médico em sua tarefa de análise e avaliação clínica.

Cabe ao docente médico a tarefa maior de todas: ensinar que a medicina está sempre a serviço do homem e que tudo quanto a ciência e a tecnologia puderam acrescentar não poderá pôr em questionamento esta afirmação. Ela repete o que Miguel Couto já dizia: "ou o homem humaniza a ciência ou a ciência irá desumanizar o homem". Tal como repete a lição maior de Osler: "tão importante quanto conhecer a doença que o homem tem é conhecer o homem que tem a doença". ${ }^{13}$

\section{REFERÊNCIAS BIBLIOGRÁFICAS}

1. Aguayo AM. Didática da Escola Nova. São.Paulo: Comp. Edit. Nacional, 1935.

2. Bigge ML. Teorias de aprendizagem para professores. São Paulo: Edit. Ped. Univ, 1977.

3. Cunningham VF. Introduçāo à educação. Porto Alegre: Globo, 1960.

4. Dewey J. Democracy and Education. New York: Mac Millan, 1916

5. Ertmer PA, Newry CJ. Behaviourism, Cognitivism, Constructivism. In: Preparing Critical Features from Instructional Design Perspective. Performance Improvement Quarterly. 1993; 6: 50-72. 
6. Ferreira J. O médico como professor- uma abordagem pedagógica. Rev. Bras. Educ. Med. 1979; 3,2:60-67.

7. Flexner A. Medical education in United States and Canadá. A report to the Carnegie Foundation of the Advancement of Teaching. Boston: Updyke, 1910 ,

8. Komatsu RS. Aprendizagem baseada em problemas: um caminho para a transformaçăo curricular. Rev. Bras. Educ. Med. 1999; 23: 32-7.

9. Lima-Gonçalves E. Teorias da aprendizagem e educação médica. Rev. Hosp. Clin. Fac. Méd. S. Paulo. 1996; 51: 10611.

10. Lima-Gonçalves E. Os objetivos da educação médica. Rev. Bras. Educ. Med. 1998; 22: 9-19.

11. Maehr M. Meaning and a motivation: toward a theory of personal investment. In Ames RE, Ames C. Motivation in Education? Student motivation. San Diego: Academic Press, 1984.
12. Newman JH. Idea of a University. In: Cunningham V F. Introduçào à educação. Porto Alegre: Globo, 1960.

13. Osler N. Aequanimitas. Philadelphia: Blakiston Co, 1932.

14. Piaget J. A equilibração das estruturas cognitivas. Rio de Janeiro: Zahar, 1978.

15. Skinner BF. Cummulative Records. New York: Appleton Century Crafts, 1959 .

Endereço para correspondência

Prof. Ernesto Lima Gonçalves

Centro de Desenvolvimento de Educação Médica

Av. Dr. Arnaldo, $455-2^{2}$ andar

CEP: $01246-903$ - São Paulo-SP 